Eur. J. Clin. Chem. Clin. Biochem.

Vol. 32, 1994, pp. 153-159

(c) 1994 Walter de Gruyter \& Co. Berlin · New York

\title{
Determination of Porphyrins in Bile Using High Performance Liquid Chromatography and Some Clinical Applications
}

By G. J. J. Beukeveld ${ }^{1}$, L. Meerman ${ }^{2}$, J. R. Huizenga ${ }^{2}$, E. E. A. Venekamp-Hoolsema ${ }^{1}$, C. H. Gips ${ }^{2}$ and B. G. Wolthers ${ }^{1}$

1 Department of Clinical Chemistry

2 Department of Internal Medicine

University Hospital, Groningen, The Netherlands

(Received September 29/November 30, 1993)

Summary: A simple and fast HPLC method for the determination of porphyrins in bile without extraction is described. Porphyrins were determined in bile from control subjects and from patients after orthotopic liver transplantation, including three patients with erythropoietic protoporphyria. It was found that:

1) coproporphyrin I is the predominant porphyrin in bile of controls, accompanied by some coproporphyrin III and protoporphyrin, whereas protoporphyrin mostly but not always is the predominant porphyrin in the bile of erythropoietic protoporphyria patients. In two of the three erythropoietic protoporphyria patients, the bile contained a hundred times more protoporphyrin than that of non-porphyric orthotopic liver transplantation patients. The third erythropoietic protoporphyria patient remained cholestatic and was unable to excrete sufficient amounts of protoporphyrin.

2) All investigated bile samples contained no secondary porphyrins derived from protoporphyrin, i. e. no deutero-, pempto-, or mesoporphyrin. Even when extracts of bile and serum were concentrated fifty to a hundred times, no traces of deutero-, pempto- and mesoporphyrin were detected. This complete absence of secondary porphyrins suggests that an enterohepatic circulation of dicarboxylic porphyrins from the distal gastrointestinal tract does not exist.

3) The HPLC chromatograms contain peaks from unknown compounds. No correlation between porphyrins and these compounds was found.

Porphyrin profiles were followed in the bile of some orthotopic liver transplantation patients. Three episodes are recognizable. During the first three days after orthotopic liver transplantation there is a very high coproporphyrin excretion. There is then a lag of one to three weeks, in which no or very low porphyrin concentrations are detectable, followed by the restoration of normal biliary porphyrin patterns.

\section{Introduction}

Determination of porphyrin profiles in biological samples by means of HPLC has proved valuable in the diagnosis and treatment of patients suffering from currently known forms of porphyria, all caused by a deficiency or inhibition of enzymes involved in the synthesis of haem.
The porphyric diseases can be identified by profiling of urine, faeces or blood $(1-3)$, and detecting the porphyrins that are greatly elevated. Thus, together with their clinical presentation, congenital erythropoietic porphyria, porphyria cutanea tarda and attacks of acute intermittent porphyria can be identified by analysis of urine, whereas stool analysis is needed to identify at- 
tacks of hereditary coproporphyria and variegate porphyria. Erythropoietic protoporphyria can be confirmed by analysis of the protoporphyrin content of erythrocytes. In many clinical laboratories, such determinations are presently performed on a routine basis.

So far, not much attention has been paid to porphyrin profiles in human bile, since the diagnosis and follow up of porphyria can be satisfactorily carried out by analysing urine, faeces or blood. However, for asymptomatic patients with porphyria those methods are not always sufficiently discriminatory. Bile was recently successfully used for the evaluation of asymptomatic patients with variegate porphyria (4). For some weeks following orthotopic liver transplantation, which is a regular operation in our hospital, bile is removed via a T-drain. For the following reasons, we decided to exploit this ready source, in order to determine the porphyrin composition of bile. First, the HPLC method, practised in our laboratory for the specific determination of porphyrins, analyses a wide variety of biological samples, using simple and essentially similar purification steps. Therefore we expected no problems in adapting the method for the analysis of bile. Secondly, three of the many patients underwent transplantation following liver failure due to longstanding erythropoietic protoporphyria. In this disease protoporphyrin is produced in abnormal amounts, mainly in erythrocytes and also in liver, due to ferrochelatase deficiency. The hydrophobic protoporphyrin molecules accumulate in the liver and have to be removed by excretion in bile. Although protoporphyrin is potentially toxic, most erythropoietic protoporphyria patients manage to preserve a reasonable liver function, because the raised quantity of produced protoporphyrin can still be adequately excreted in the bile. However, after the gradual accumulation of protoporphyrin, some erythropoietic protoporphyria patients suffer from irreversible liver damage and finally liver failure, requiring orthotopic liver transplantation in order to survive $(5-10)$. After transplantation, the patients have to be monitored regularly for the ability of the liver to adequately excrete the continuing excessive production of protoporphyrin from bone marrow, because of the risk of renewed liver failure (9). For these reasons we considered it of clinical interest to compare the biliary excretion of porphyrins of erythropoietic protoporphyria patients in the weeks after orthotopic liver transplantation with that of orthotopic liver transplantation patients operated for liver failure from other diseases.

Further we had at our disposal a number of samples from different patients after duodenal intubation, i. e. A bile (fasting duodenal content), B (gall bladder) bile and $\mathrm{C}$ (hepatic) bile. The porphyrin profiles of these samples were investigated and compared with bile from orthotopic liver transplantation patients.
Since none of the bile samples contained traces of porphyrins derived from the bacterial conversion of endogenous porphyrins in the gut (i.e. secondary porphyrins like meso-, pempto- and deuteroporphyrin (3)), we reinvestigated the controversial issue of the existence of an enterohepatic circulation for 'porphyrins $(11-14)$. For this purpose large amounts of bile and serum were purified for analysis of porphyrins. These concentrated extracts were investigated for the presence of secondary porphyrins, but these appeared to be absent. As discussed in this paper, this does not support the hypothesis that dicarboxylic porphyrins, including protoporphyrin, are subject to enterohepatic circulation from the lower gastrointestinal tract. Altogether the results of HPLC porphyrin profiling in human bile described in this paper confirm that such determinations constitute a useful extension of the available procedures for porphyrin profiling in clinical laboratories in certain clinical conditions.

\section{Materials and Methods}

Patients and samples

Porphyrins were studied in the bile of two different groups of patients. The first group of six subjects had undergone an orthotopic liver transplantation, three of them on account of erythropoietic protoporphyria. The second group consisted of 11 subjects who for different reasons were intubated for gall bladder investigations. The orthotopic liver transplantation procedure in our hospital has been described earlier (15). The biliary procedure was an end-to-end choledochocholedochostomy over a bile-tube and removal of the gall bladder. After 3-4 weeks, or later if indicated, the tube was clamped, then removed after some days.

The intubation procedure to obtain A-, B-, and C-bile was described previously (16). The intubation was performed in patients who had fasted for at least 14 hours; a plastic tube with a metallic end was positioned in the third part of the duodenum, using fluoroscopic monitoring. A-bile (fasting duodenal contents, consisting of secretions from the pancreas, bile ducts and duodenum) was aspirated, whereafter contraction of the gall bladder was stimulated by intravenous administration of cholecystokinin. Within 10-15 minutes after the injection, dark gall bladder bile was aspirated (Bbile). After 45 to 60 minutes a third sample of light-coloured aspirate was drawn (C-bile). This $\mathrm{C}$-bile consists mainly of hepatic bile with pancreatic and duodenal secretions (16).

Bile samples of the patients were obtained with regard to the rules of the Medical Ethical Committee of our bospital. The samples were protected from light as much as possible and were stored frozen without preservation prior to analysis.

\section{Porphyrin analysis}

Bile

Two-hundred $\mu \mathrm{l}$ of bile, $200 \mu \mathrm{l}$ of $3 \mathrm{~mol} / \mathrm{l} \mathrm{HCl}$ and $100 \mu \mathrm{l}$ of an internal standard solution (500 nmol/1 deuteroporphyrin (Porphyrin Products, Logan, USA) in a $0.8 \mathrm{~mol} / 1$ sulphosalicylic acid solution) were mixed in an Eppendorf cup. After centrifugation, $40 \mu$ lof the clear supernatant was injected onto the HPLC column.

The porphyrins of bile were eluted under the same conditions as porphyrins of urine, blood and faeces. Details of these methods including the use of internal standard were described previously $(2,3)$. 
During the development of the determination of porphyrins in bile the sample volume and its predilutions were chosen so that normal bile samples give peak heights comparable to those seen in normal urine, blood and faecal samples.

\section{Traces in bile}

For the determination of traces of porphyrins in bile the following procedure was used. A bile solution of $100 \mathrm{ml}$, obtained from fractions of bile of different subjects, was divided into two equal portions. To one portion the internal standard deuteroporphyrin was added. Porphyrins were extracted twice with $100 \mathrm{ml}$ of a freshly prepared ether - glacial acetic acid solution $(3+1$, by vol.). In a waterbath set at $37^{\circ} \mathrm{C}$ the extracts were evaporated to dryness by means of a nitrogen stream. The porphyrins were dissolved in $1 \mathrm{ml}$ of $6 \mathrm{~mol} / \mathrm{l} \mathrm{HCl}$ solution, and $40 \mu \mathrm{l}$ of the acid solution was injected onto the HPLC column.

\section{Traces in serum}

Due to the low porphyrin and high protein concentrations in serum compared with bile, the porphyrin extraction procedure for serum completely differs from that of bile. The porphyrins were extracted according to a combination of methods described by Falk (17). Briefly, a portion of $200 \mathrm{ml}$ serum, pooled from more than 50 different subjects, was divided into two equal portions. To one portion the internal standard deuteroporphyrin was added. To the sera a mixture of $500 \mathrm{ml}$ of ethyl acetate and glacial acetic acid (3+ 1 , by vol.) was added slowly with vigorous stirring and the mixtures were allowed to stand for three hours. The precipitated proteins were removed on a Büchner funnel, and washed well two times with $100 \mathrm{ml}$ of an ethyl acetate - acetic acid mixture $(3+1$, by vol.). The protein residues may still contain considerable amounts of uroporphyrins, but since we were concerned only with tetra- and dicarboxylic porphyrins no further attention was paid to the uroporphyrins. The combined filtrates were transferred to a separating funnel, and washed twice with $300 \mathrm{ml}$ of a saturated sodium acetate solution. The washings were extracted twice with $100 \mathrm{ml}$ of ethyl acetate. The ethyl acetate layers were added to the main ethyl acetate - acetic acid layers. The combined ethyl acetate layers were washed once with $100 \mathrm{ml}$ of $0.2 \mathrm{~mol} / \mathrm{l}$ sodium acetate solution. The porphyrins were extracted completely from the ethyl acetate - acetic acid solution with 2 portions of $50 \mathrm{ml}$ of a $4 \mathrm{~mol} / \mathrm{l}$ $\mathrm{HCl}$ solution. In a separating funnel the porphyrins were transferred from the combined $\mathrm{HCl}$ extract into $500 \mathrm{ml}$ ether by adjusting the $\mathrm{pH}$ to about 4 with a solution of $4 \mathrm{~mol} / \mathrm{l} \mathrm{NaOH}$ and $50 \mathrm{ml}$ of a saturated sodium acetate solution. The mixture was shaken frequently thus preventing precipitation of porphyrins. The aqueous layers were re-extracted twice with fresh ether, and the ether fractions were combined. The combined ether layers were washed once with $100 \mathrm{ml}$ of $0.2 \mathrm{~mol} / 1$ sodium acetate solution, and their volumes were reduced by $95 \%$ under a nitrogen stream. The porphyrins were extracted in $500 \mu \mathrm{l}$ of $6 \mathrm{~mol} / 1 \mathrm{HCl}$, and $200 \mu \mathrm{l}$ of this solution was injected onto the HPLC column.

\section{Reproducibility, linearity and recovery}

The intra-assay coefficient of variation of the method was determined with bile containing normal coproporphyrin I and III concentrations and a high content of protoporphyrin $(2.5 \mu \mathrm{mol} / \mathrm{l})$. This sample was assayed 10 times in the same run. The linearity of the method was determined by analysing two biles with a high coproporphyrin I and protoporphyrin content, respectively, in increasing volumes $(10,20,50,100,200,300$, and $400 \mu l)$ to which $100 \mu \mathrm{l}$ of internal standard and $\mathrm{HCl}$ solution $(3 \mathrm{~mol} / \mathrm{l})$ were added to an end volume of $600 \mu \mathrm{l}$. The recoveries of coproporphyrin I and protoporphyrin were determined in normal bile fortified with 100 and $30 \mathrm{nmol} / 1$, respectively.

\section{Results}

Chromatograms of bile porphyrins after orthotopic liver transplantation are shown in figure 1 (la and $1 \mathrm{c}$, nonerythropoietic protoporphyria patients; $1 \mathrm{~b}$ and $1 \mathrm{~d}$, a single patient at different times after orthotopic liver transplantation). The following porphyrins were found to be present in bile: coproporphyrin I and III (peaks numbered 1 and 2) and protoporphyrin (peak 4). Clearly the erythropoietic protoporphyria patient excretes considerably more protoporphyrin in bile. From figure 1, one can further deduce that bile contains no pempto-, and mesoporphyrin (peaks numbered 7 and 8 ), while deuteroporphyrin (peak 3 ) also appeared to be absent when omitted as an internal standard (not shown in fig. 1). In order to ascertain that bile and serum contained not even traces of these porphyrins, we concentrated normal bile and serum extracts about fifty to two hundred times (compared with routine procedures) and injected these extracts onto the HPLC column. The results of these experiments are shown in figure 2 (2a: bile with, $2 \mathrm{~b}$ : bile without internal standard, $2 c$ : serum with internal standard, 2d: plain serum) and they demonstrate again that no traces of deutero-, pempto-, and mesoporphyrin are present in bile or serum. There is therefore no objection taking deuteroporphyrin as the internal standard for the determination of biliary porphyrins. Figures 1 and 2 show that peaks (numbered 5 and 6 ) of unknown compounds are also found, eluting between copro- and deuteroporphyrin. Investigation of many other bile samples revealed that the peak heights of these unknown compounds did not correlate with those of protoporphyrin (see for example the chromatograms shown in fig. 1).

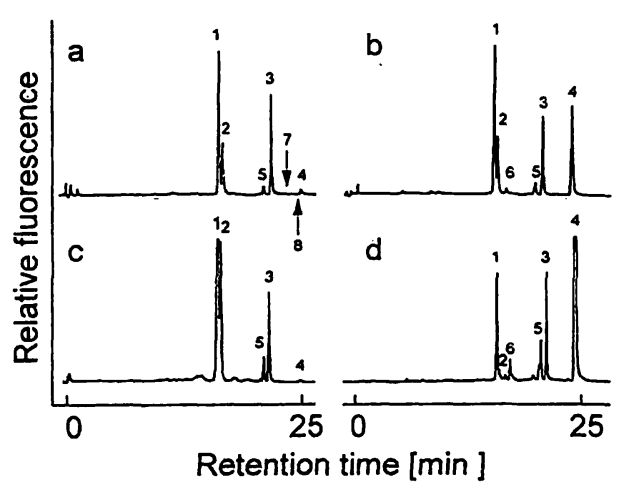

Fig. 1 Chromatograms of porphyrins in bile of patients who underwent an orthotopic liver transplantation. Chromatograms la and $1 \mathrm{c}$ are obtained from patients not suffering from a porphyric disease. Depicted are porphyrins in bile two days (1c) and three weeks (1a) after orthotopic liver transplantation. Chromatogram Ib and ld are from one patient with erythropoietic protoporphyria, 50 and 56 days after orthotopic liver transplantation, respectively. Bile for $1 \mathrm{~d}$ was collected during a surgical operation for peptic ulceration. Numbering:

$1=$ coproporphyrin I, 2 = coproporphyrin III, 3 = internal standard deuteroporphyrin, $4=$ protoporphyrin, 5 and 6 unknoun compounds, $7=$ pemptoporphyrin, $8=$ mesoporphyrin. 
Because of their porphyric-like fluorescence it is tempting to speculate that these unknown compounds possess a porphyrin structure. Although of potential clinical interest, we have not attempted to study further the nature of the compounds represented by these peaks.

Figure 3 shows data for the time course of concentration changes of coproporphyrin I and protoporphyrin in bile of different patients after orthotopic liver transplantation. Figures $3 \mathrm{a}$ and $3 \mathrm{~b}$ represent results of three erythropoietic protoporphyria patients (one of them died half a year after orthotopic liver transplantation, the other two

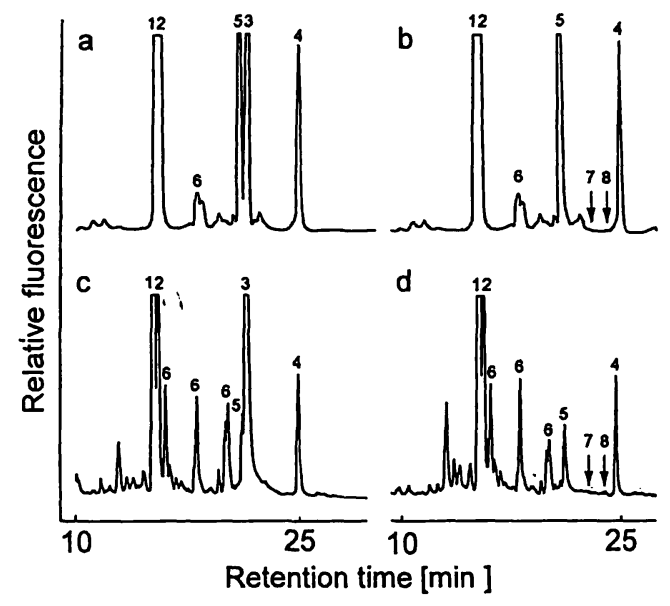

Fig. 2 Chromatograms of porphyrins in extracts of bile and serum, showing the absence of secondary porphyrins in these body fluids. Bile (2a and $2 b$ ) is concentrated fifty, and serum ( $2 c$ and $2 d$ ) two hundred times.' To the extracts $2 a$ and $2 c$, the internal standard deuteroporphyrin was added, to final concentrations of 50 and 75 nmol/l, respectively.

For explanations of the numbers see figure 1 .

In both serum and bile, coproporphyrin I is the most prominent porphyrin. the copro I/proto ratio in this serum pool is 4.4. The estimated protoporphyrin concentration in the serum pool is about $70 \mathrm{pmol} / \mathrm{l}$. are still alive three years after orthotopic liver transplantation). Figures $3 \mathrm{c}$ and $3 \mathrm{~d}$ depict results of three orthotopic liver transplantation subjects, who were transplanted because of primary biliary cirrhosis $(n=1)$, chronic active $(n=1)$ and inactive cirrhosis $(n=1)$.

Table 1 presents a survey of the results of porphyrin concentrations in A-, B-, and C-bile of a number of patients.

The coefficients of variation for intra-run precisions measured for coproporphyrin I, coproporphyrin III and protoporphyrin were $2.1,5.3$ and $1.1 \%(n=10)$, respectively. The method was linear up to $4 \mu \mathrm{mol} / 1$ for all porphyrins, while recoveries for coproporphyrin I and protoporphyrin were $>95 \%$.

\section{Discussion}

Reports of determinations of porphyrins in bile are scanty, partly due to the fact that bile is not easily available and partly because analysis of bile is not essential for the diagnosis and follow up of porphyric patients. However, in a recent report, the analysis of porphyrins in bile proved to be superior to the analysis in faeces in establishing the diagnosis of variegate porphyria, as the difference between normal and pathological porphyrin excretions in bile was greater than in faeces (4). Moreover, investigation of biliary porphyrins provides information on the ability of the liver to excrete the different porphyrins. In contrast to uro- and coproporphyrins, highly hydrophobic protoporphyrin can only be excreted in bile, hepatic secretion being rate limiting (19). In the case of erythropoietic protoporphyria, the increased blood protoporphyrin tends to accumulate in the liver, which firstly can lead to cholestasis and eventually to

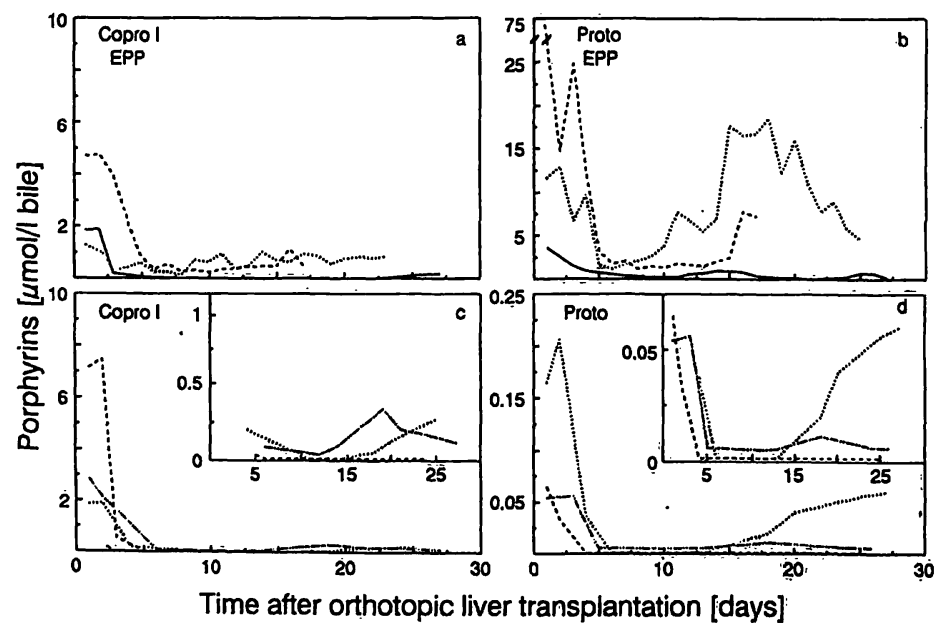

Fig. 3 Time course profiles of coproporphyrin I (copro I) and protoporphyrin (proto) in bile of patients who underwent an orthotopic liver transplantation. In figure $3 a$ and $3 b$ the profiles of three erythropoietic protoporphyria patients (EPP) are shown, whereas in fig- ure $3 \mathrm{c}$ and $3 \mathrm{~d}$ profiles of three non-porphyric patients are depicted. The solid line in figure $3 a$ and $3 b$ represents the erythropoietic protoporphyria patient with a putative cholestatic liver. 
Tab. 1 Survey of the porphyrin analyses of A-, B-, and C-bile from patients who underwent a duodenal intubation.

\begin{tabular}{|c|c|c|c|c|}
\hline & Mean & Median & Minimal & Maximal \\
\hline \multicolumn{5}{|l|}{$\begin{array}{l}\text { Coproporphyrin I } \\
(\mathrm{nmol} / \mathrm{l})\end{array}$} \\
\hline $\begin{array}{l}\text { A-bile }(n=11) \\
\text { B-bile }(n=9) \\
\text { C-bile }(n=10)\end{array}$ & $\begin{array}{l}158 \\
249 \\
139\end{array}$ & $\begin{array}{l}103 \\
244 \\
111\end{array}$ & $\begin{array}{l}31 \\
83 \\
27\end{array}$ & $\begin{array}{l}378 \\
363 \\
309\end{array}$ \\
\hline \multicolumn{5}{|l|}{$\begin{array}{l}\text { Coproporphyrin III } \\
(\mathrm{nmol} / \mathrm{l})\end{array}$} \\
\hline $\begin{array}{l}\text { A-bile } \\
\text { B-bile } \\
\text { C-bile }\end{array}$ & $\begin{array}{l}71 \\
77 \\
47\end{array}$ & $\begin{array}{l}30 \\
87 \\
36\end{array}$ & $\begin{array}{l}11 \\
33 \\
11\end{array}$ & $\begin{array}{l}411 \\
147 \\
134\end{array}$ \\
\hline \multicolumn{5}{|l|}{$\begin{array}{l}\text { Protoporphyrin } \\
(\mathrm{nmol} / \mathrm{l})\end{array}$} \\
\hline $\begin{array}{l}\text { A-bile } \\
\text { B-bile } \\
\text { C-bile }\end{array}$ & $\begin{array}{r}9 \\
11 \\
12\end{array}$ & $\begin{array}{c}<0.5 \\
6 \\
6\end{array}$ & $\begin{array}{l}<0.5 \\
<0.5 \\
<0.5\end{array}$ & $\begin{array}{l}22 \\
29 \\
32\end{array}$ \\
\hline \multicolumn{5}{|l|}{ Copro I/copro I + III } \\
\hline $\begin{array}{l}\text { A-bile } \\
\text { B-bile } \\
\text { C-bile }\end{array}$ & $\begin{array}{l}0.76 \\
0.76 \\
0.75\end{array}$ & $\begin{array}{l}0.79 \\
0.80 \\
0.79\end{array}$ & $\begin{array}{l}0.48 \\
0.50 \\
0.47\end{array}$ & $\begin{array}{l}0.86 \\
0.88 \\
0.82\end{array}$ \\
\hline \multicolumn{5}{|c|}{ Copro Vprotoporphyrin } \\
\hline $\begin{array}{l}\text { A-bile } \\
\text { B-bile } \\
\text { C-bile }\end{array}$ & $\begin{array}{l}18 \\
26 \\
18\end{array}$ & $\begin{array}{l}- \\
13 \\
18\end{array}$ & $\overline{-}$ & $\begin{array}{l}30 \\
48 \\
28\end{array}$ \\
\hline
\end{tabular}

terminal liver failure, requiring orthotopic liver transplantation for survival. The fact that bile can be obtained from orthotopic liver transplantation patients during the first weeks after the operation enabled us to compare the biliary porphyrin excretion, in particular of orthotopic liver transplantation, of three transplanted erythropoietic protoporphyria patients with that of some non-erythropoietic protoporphyria patients. As shown by the chromatograms in figure 1 and the quantitative data in figure 3 (time course of porphyrin concentrations in the bile of 3 erythropoietic protoporphyria patients and 3 nonerythropoietic protoporphyria patients after orthotopic liver transplantation), biliary protoporphyrin is always much higher in erythropoietic protoporphyria patients than in non-erythropoietic protoporphyria patients (in quantitative terms more than a hundred fold), whereas biliary coproporphyrin I and III excretion in erythropoietic protoporphyria patients is only slightly higher. These results clearly demonstrate that in erythropoietic protoporphyria the high amounts of protoporphyrin mainly originate from the erythropoietic system in bone marrow. Figure 3 also shows that in the first 5 days after orthotopic liver transplantation both coproporphyrins and protoporphyrin are excreted in huge amounts, which then return to very low values, later tending to rise somewhat again. The reason for the strikingly raised biliary porphyrin excretion in the first days after orthotopic liver transplantation cannot be given with certainty and is the subject of further study. It might be ascribed to the accumulation of porphyrins produced in the donor liver in the period between its removal and the time that transplantation took place and/or to the accumulation of porphyrins in the host during the operation phase. After transplantation these accumulated porphyrins could then be washed out. After approximately 5 days, a new steady state situation is attained, in which the production and excretion of porphyrins match again, and this washout would no longer occur. To our knowledge, porphyrins are the only compounds excreted in highly increased amounts immediately after orthotopic liver transplantation (15).

During the 5-15 days after orthotopic liver transplantation a temporary difficulty in excretion of porphyrins might be the case, or a low porphyrin de novo synthesis due to liver regeneration, thus explaining the relatively low biliary excretion of porphyrins in that period. However, in two of the three erythropoietic protoporphyria patients, 10-15 days after orthotopic liver transplantation, protoporphyrin values show a sustained rise to very high levels, which vary greatly in individual patients from day to day.

The third erythropoietic protoporphyria patient (see fig. 3) continuously excreted considerably less protoporphyrin than the other two erythropoietic protoporphyria patients, despite high protoporphyrin concentrations in blood $(15 \mu \mathrm{mol} / 1$, normal $<0.56 \mu \mathrm{mol} / \mathrm{l})$. Also his protoporphyrin concentrations in serum were increased (data not shown), reflecting the absence of good liver function (18). He had severe cholesterasis and died half a year after orthotopic liver transplantation. Retrospectively it can be stated that even from the start of orthotopic liver transplantation he probably had difficulties in adequately excreting protoporphyrin, leading to an accumulation of protoporphyrin, which in turn contributed to early liver failure (18). Protoporphyrin was undetectable in the serum of the other orthotopic liver transplantation patients and the other two erythropoietic protoporphyria patients, using our method, which has a detection limit of $<0.5 \mathrm{nmol} / \mathrm{l}$ (data not shown).

The complete absence of deutero-, pempto- and mesoporphyrins in the bile of orthotopic liver transplantation patients (see fig. 1) as well as in A-, B- and C-bile (chromatograms not shown) motivated us to investigate the question of whether or not an enterohepatic circulation of porphyrins operates in humans. These latter porphyrins are produced in the gut as a result of reductive conversion of protoporphyrin by anaerobic bacteria and are markedly present in faeces $(3,19,20)$. If an enterohepatic circulation exists, there should be evidence of these "secondary" porphyrins in serum and bile, analogous to 
the presence of secondary bile acids (deoxycholic acid and lithocholic acid) in serum and bile, produced in the gut by bacterial conversion of primary bile acids (cholic acid and chenodeoxycholic acid). In the literature the enterohepatic circulation of porphyrins constitutes a controversial issue. Some reports state that such a circulation exists $(11-13)$, whereas others state the reverse (14). It might be that secondary porphyrins are present in bile or serum in trace amounts. To exclude this possibility we worked up portions of $50 \mathrm{ml}$ of collected bile and $100 \mathrm{ml}$ of pooled serum, each with and without internal standard (deuteroporphyrin). As figures $2 a-d$ demonstrate, even in the concentrated extracts of bile and serum no traces of secondary porphyrins could be detected, which does not support the hypothesis that porphyrins are subject to enterohepatic circulation at the lower part of the gastrointestinal tract. This finding does not exclude the presence of an enterohepatic circulation of copro- and uroporphyrins nor the absorption of protoporphyrin at the upper part of the gut. In one of our previous studies it was demonstrated that in normal subjects more than $90 \%$ of the primary porphyrins in faeces (protoporphyrin and coproporphyrins) and all of the secondary porphyrins are synthesized by bacteria in the lower part of the small bowel and colon (3). Since dicarboxylic porphyrins are not absorbed in these parts, the total enterohepatic circulation of porphyrins at the upper part of the gastrointestinal tract, if existent, would be relatively small under normal conditions, due to the low biliary concentrations of porphyrins.

Finally, we analysed the porphyrin composition of A-, $\mathrm{B}-$ and C-bile from various patients not suffering from any of the porphyrias (see tab. 1). First of all, it is obvi- ous that the concentration of porphyrins in these bile samples varies widely. The patterns of A-, B- and Cbile, which show close resemblance with those of bile obtained from (non-erythropoietic protoporphyria) orthotopic liver transplantation patients, are not essentially different, although the mean concentrations in B-bile are higher than in A- and C-bile. Apart from two unknown compounds ("peaks 5 and 6") coproporphyrins I and III, and protoporphyrin are present. Coproporphyrin I is almost always the prominent biliary porphyrin and its concentration far exceeds that of protoporphyrin, the latter not exceeding a value of approximately $30 \mathrm{nmol} / \mathrm{l}$. The overall mean ratios coproporphyrin I/coproporphyrin I and III (copro I ratio) and coproporphyrin I/protoporphyrin are 0.76 and 21 , respectively. The same results in bile have been previously reported $(21,22)$. Similar copro I ratios also are detected in faeces $(2,22)$. Only in one case was a copro I ratio of less than 0.50 (coproporphyrin III concentration exceeding that of coproporphyrin I) found. In contrast to bile, normal faecal protoporphyrin concentrations (and its derivatives deutero-, pempto- and mesoporphyrin) often markedly exceed those of coproporphyrin I. This can be attributed to both bacterial production and conversion of protoporphyrin in the gut $(3,19,20)$.

To summarize, the profiling of porphyrins in bile reveals interesting aspects of their hepatic clearance, and shows that their quantitative determination can be of value in some clinical situations, e.g. the follow up of protoporphyrin excretion in erythropoietic protoporphyria patients after orthotopic liver transplantation. The absence of secondary porphyrins in bile (and serum) suggests the absence of an enterohepatic circulation for dicarboxylic porphyrins.

\section{References}

1. Lim, C. K. \& Peters, T. J. (1984) Urine and faecal porphyrin profiles by reversed-phase high-performance liquid chromatography in porphyrias. Clin. Chim. Acta 139, 55-63.

2. Beukeveld, G. J. J., Nagel, G. T., de Ruyter-Buitenhuis, A. W., Kwarts, E. W. \& Wolthers, B. G. (1987) Determination of porphyrins in blood, urine and faeces by means of HPLC and its application in establishing porphyrias. Biochimica Clinica $11,203-213$.

3. Beukeveld, G. J. J., Wolthers, B. G., van Saene, J. J. M., de Haan, T. H. I. J., de Ruyter-Buitenhuis, A. W. \& van Saene, R. H. V. (1987) Patterns of porphyrin excretion in faeces as determined by liquid chromatography: Reference values and the effect of flora suppression. Clin. Chem. 33, 2164-2170.

4. Logan, G. M., Weimer, M. K., Ellefson, M., Pierach, C. A. \& Bloomer, J. R. (1991) Bile porphyrin analysis in the evaluation of variegate porphyria. N. Eng. J. Med. 324, 1408-1411.

5. Bloomer, J. R., Weimer, M. K., Bossenmaier, I. C., Snover, D. C., Payne, W. D. \& Ascher, N. L. (1989) Liver transplantation in a patient with protoporphyria. Gastroenterology 97, 188194.

6. Polson, R. J., Lim, C. K., Rolles, K., Calne, R. Y., Williams, $R$. (1988) The effect of liver transplantation in a 13 year-old boy with erythropoietic protoporphyria. Transplantation 46, 386-389.

7. Samuel, D., Boboc, B., Berneau, J., Bismuth, H. \& Benhamou, J. P. (1988) Liver transplantation for protoporphyria. Gastroenterology $95,816-819$.

8. Mion, F. B. C., Faure, J. L., Berger, F., McGregor, B., Perrot, H. \& Paliard, P. (1992) Liver transplantation for erythropoietic protoporphyria, Report of a new case with subsequent medium-term follow-up. J. Hepatol. 16, 203.

9. Steinmüller, T., Doss, M. O., Steffen, R., Blumhardt, G., Bechstein, W. O., Frank, M., Sieg, I., Kretschmar, R. \& Neuhaus, P. (1992) Lebertransplantation bei erythrohepatischer Protoporphyrie. Dtsch. Med. Wochenschr. 117, 1097-1102.

10. Shehade, S. A., Chalmers, R. J. G. \& Prescott, R. J. (1991) Predictable and unpredictable hazards of erythropoietic protoporphyria. Clin. Exp. Dermatol. 16, 185-187.

11. Ibrahim, G. M. \& Watson, J. C. (1968) Enterohepatic circulation and conversion of protoporphyrin to bile pigment in man. Proc. Soc. Exp. Biol. Med. 727, 890-895. 
12. McCullough, F. A., Barron, D., Mullen, K. D., Petrelli, M., Park, M. C., Mukhtar, H. \& Bickers, D. R. (1988) Faecal protoporphyrin excretion in erythropoietic protoporphyria: Effect of cholestyramine and bile acid feeding. Gastroenterology 94, 177-181.

13. Pimstone, N. R., Gandhi, S. N. \& Mukerji, S. K. (1987) Therapeutic efficacy of oral charcoal in congenital erythropoietic porphyria. N. Eng. J. Med. 316, 390-393.

14. Stathers, G. M., Aronsen, K. F. \& Haeger-Aronsen, B. (1969) Studies on the entero-hepatic circulation of ${ }^{14} \mathrm{C}$ porphyrins. Br. J. Dermatol. 81, 276-279.

15. Krom, R. A. F., Gips, C. H., Houthoff, H. J., Newton, D., van der Waaij, D., Beelen, J., Haagsma, E. B. \& Sloof, M. J. H. (1984) Orthotopic liver transplantation in Groningen, the Netherlands (1979-1983). Hepatology 4, 61S-65S.

16. Sulaiman, A. \& Gips, C. H. (1974) Identification of gallbladder bile (B-bile) during duodenal intubation. Tijdschrift voor Gastro-Enterologie 17, 373-382.

17. Falk, J. E. (1964) Porphyrins and Metalloporphyrins. Elsevier Publ. Comp. Amsterdam, B. B. A. Library, vol. 2.

18. Avner, D. L. \& Berenson, M. M. (1982) Hepatic clearance and biliary resecretion of protoporphyrin in isolated, in situperfused rat liver. J. Lab. Clin. Med. 99, 885-894.
19. Grosser, Y. \& Eales, L. (1973) Pattern of faecal porphyrin excretion in the hepatocutaneous porphyrias. S-Afr. Med. J. 47, 2162-2168.

20. Rose, I. S., Young, G. P., St-John, D. J. B., Deacon, M. C., Blake, D. \& Henderson, R. W. (1989) Effect of ingestion of hematoproteins on faecal excretion of hemes and porphyrins. Clin. Chem. 35, 2290-2296.

21. Aziz, M. A. \& Watson, C. J. (1969) An analysis of the porphyrins of normal and cirrhotic human liver and normal bile. Clin. Chim. Acta 26, 525-531.

22. Rocchi, E., Gibertini, P., Santunione, V., Balli, F. \& Ventura, E. (1980) Faecal and urinary coproporphyrin isomers in biliary atresia and neonatal hepatitis. La Ricerca Clin. Lab. 10, 501-509.

Drs. G. J. J. Beukeveld

Dept. of Clinical Chemistry University Hospital Groningen

Oostersingel 59

NL-9713 EZ Groningen

The Netherlands 
